\title{
The Total Syntheses of JBIR-94 and Two Synthetic Analogs and Their Cytotoxicities Against A549 (CCL-185) Human Small Lung Cancer Cells
}

Cathy L. Mangum ${ }^{a}$, Mica B. Munford ${ }^{a}$, Alyssa B. Sam ${ }^{a}$, Sandra K. Young ${ }^{a}$, Jeremy T. Beales ${ }^{a}$, Yagya Prasad Subedi ${ }^{b}$, Chad D. Mangum ${ }^{a}$, Tanner J. Allen ${ }^{a}$, Miranda S. Liddell ${ }^{a}$, Andrew I.

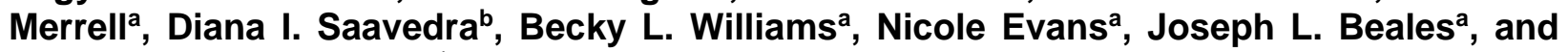
Michael A. Christiansen ${ }^{a},{ }^{*}$

a Utah State University, Uintah Basin Campus: 320 North Aggie Blvd, Vernal, UT 84078, U.S.A.

b Utah State University, Logan Campus: Department of Chemistry \& Biochemistry, Logan, UT 84322-0300, U.S.A.

c Brigham Young University, Department of Chemistry \& Biochemistry, Provo, UT 84602, U.S.A

* $\quad$ Corresponding author. Tel./fax: +1 4357221761

E-mail address: m.christiansen@usu.edu (M. A. Christiansen)

\begin{abstract}
We here disclose the total syntheses of the natural polyphenol JBIR-94 and two nonnatural analogs, whose structures are of interest for their bioactivity potential as radical scavengers. Although we initially attempted this by dually acylating both of putrecine's amine nitrogens in a single pot, our endeavors with this method (which has been successfully reported by other groups) proved ineffectual. We accordingly opted for the lengthier approach of acylating each amine individually, which gratuitously prevailed and also aligns with separate literature precedent. Moreover, we here share our analysis of these target compounds' cytotoxicities and $\mathrm{IC}_{50}$ values against A549 (CCL-185) human small lung cancer cells.
\end{abstract}

\section{Keywords}

Radical oxygen

JBIR

Natural products

Putrecine

\section{Introduction}

In the human body, the unavoidable exposure of living tissues to excess free radicals, such as reactive oxygen species, can result in oxidative modification of biomolecules. ${ }^{1}$ These events contribute to various disorders that include age-related degenerative conditions, mutagenesis, neural dysfunction, cancer, heart disease, and compromised immune health. ${ }^{2-5}$ The human body possesses enzymatic and nonenzymatic antioxidative machinery to scavenge and eliminate free radicals, which include the dynamic $1-5 \%$ of radical molecular oxygen that human cells naturally produce. ${ }^{1,5}$ However, the efficacy of these defense mechanisms decreases with age. ${ }^{1}$ 
Fortuitously, diets rich in fresh fruits and vegetables correlate with lowered frequency of the aforementioned maladies, presumably because such foods contain high concentrations of antioxidative molecules: in particular, of polyphenolic compounds, which often possess antimutagenic, anti-inflammatory, antimicrobial, and free-radical-oxygen-scavenging properties. ${ }^{6-}$

${ }^{15}$ It follows, then, that long-term healthy eating might partly offset the negative health effects in play as we age. Beyond its relevance to health, radical oxidation is also associated with food decomposition, as it "affects food safety, color, flavor, and texture" by contributing to the deterioration of lipids. ${ }^{6}$ Thus, antioxidants might also enhance and preserve food quality. ${ }^{6,16-17}$

With our research focus on synthesizing small, bioactive natural molecules with potential implications for disease prevention, we took note of two polyphenolic compounds, JBIR-94 and JBIR-125 (1 and 2, Figure 1), which were discovered in 2012 by Takagi and Shin-ya as secondary metabolites of the bacterium Streptomyces R56-07. ${ }^{18}$ According to their report, when molecules 1 and 2 were tested in an $\alpha$-diphenyl- $\beta$-picrylhydrazyl (DPPH) assay, they exhibited free-radicalscavenging $\mathrm{IC}_{50}$ potencies of $11.4 \mu \mathrm{M}$ and $35.1 \mu \mathrm{M}$, respectively. ${ }^{18}$ By comparison, $\alpha$-tocopherol, a potent, radical-scavenging form of vitamin $E,{ }^{19-20}$ gave an $\mathrm{IC}_{50}$ value of $9.0 \mu \mathrm{M}$ in the same assay. ${ }^{18}$ Thus, the more active natural product, JBIR-94 (1), manifested radical-scavenging potency comparable to that of Vitamin E, a well-known dietary antioxidant. ${ }^{20}$

Figure 1. JBIR-94 (1), JBIR-125 (2), and synthetic analogs 3 and 4.

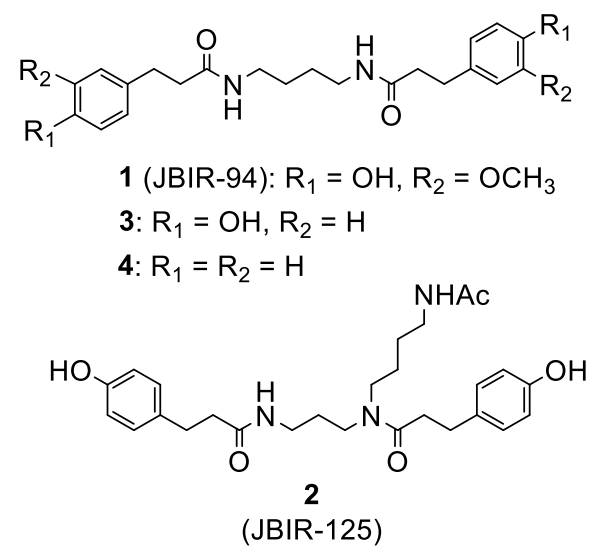

As often occurs in the field of natural products, both $\mathbf{1}$ and $\mathbf{2}$ were isolated in scant amounts from their natural source: $1.3 \mathrm{mg}(\mathbf{1})$ and $2.3 \mathrm{mg}(2)$, respectively, from $2 \mathrm{~L}$ of bacterial fermentation broth. ${ }^{18}$ Thus, large-scale access to either compound for more extensive study would be most efficiently achieved through total synthesis. As molecule 1 was the more potent of the two, we focused on its assembly, which we reasoned would be facile, given its symmetry. Because polyphenols are often reported to be potent radical scavengers, ${ }^{7-15}$ we hypothesized that the hydroxyl groups in 1 would be necessary for bioactivity but that the methoxy groups would not. Thus, analog 3 (Figure 1), which retains the hydroxyl moieties of $\mathbf{1}$ but lacks its methoxy groups, might theoretically exert similar antioxidative potency, while analog 4 , which lacks both, would not. With the goal of providing efficient access to these molecules for later analysis, we sought to develop their first total syntheses.

Despite finishing this work in mid-2016, ${ }^{21}$ time and resource constraints precluded us from an earlier disclosure. Moreover, as we initially raced toward its completion, elegant syntheses of 1 and $2,{ }^{22}$ as well as a separate synthesis of $4,{ }^{23}$ were published by other groups in late 2015, thereby diminishing the impact of our research. Nevertheless, that we are aware, analog 3 has 
never been previously reported. Thus, this paper presents the first disclosed synthesis of 3 . Additionally, we share here the results of a cytotoxicity study of $\mathbf{1}, \mathbf{3}$, and 4 , which should aid further efforts in developing bioactivity profiles for these molecules.

\section{Results and discussion}

At the outset, we envisioned a highly efficient one-pot, three-molecule assembly of the JBIR core, for which some related transformations were known. ${ }^{24}$ Thus, trans-ferulic acid (5) was treated with $\mathrm{H}_{2}$ gas and $5 \% \mathrm{Pd} / \mathrm{C}$ to quantitatively furnish 6 (Scheme 1). ${ }^{25}$ At this point, we divergently converted 6 into differentially protected analogs $7 a-c^{26-28}$ (yields shown in Scheme 1). We then individually coupled molecules 6 and 7a-c with putrecine (8) in a 2:1 ratio in anticipation of forming hydrocarbon-tethered diamides 1 (from 6 ) or $\mathbf{9 a - c}$ (from 7a-c), respectively. Coupling parameters were screened under Conditions A-D (Scheme 1, bottom-left inset). Unfortunately, all of these attempts failed and instead gave only complex mixtures, unreacted starting materials, or unidentifiable byproducts. This contrasts with the work of Sorensen and Taj, who reported using $\mathrm{EDCl}$ (Condition B) to successfully couple 7a with 8 , forming $9 \mathrm{a}$ in $63 \%$ yield. ${ }^{22}$

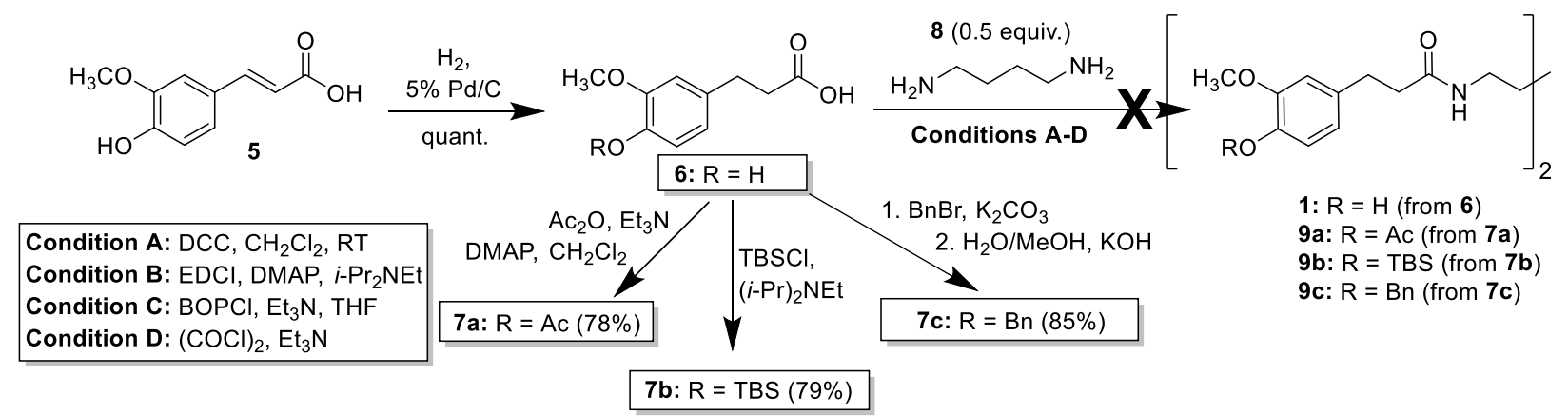

Scheme 1. Attempted three-molecule/one-pot assemblies of the JBIR-94 core.

Although this setback's exact cause was uncertain, we suspected detrimental interaction with our protecting groups - for instance, an amine displaing the acetyl appendage in 7 a-or undesired cross-reactivity between chlorine and silicon when silyl ether $\mathbf{7 b}$ is treated with oxalyl chloride (Condition D).

Thus, as an alternative approach (Scheme 2), we treated molecules 7a-b (7c was not attempted) with $N$-hydroxysuccinimide (10) and DCC to quantitatively form intermediates 11a-b, whose succinimidyl-functionalization has been reported elsewhere for assembling diamides. ${ }^{29}$ However, our efforts to obtain 11a-b in pure form were plagued with difficulties and proved unsuccessful. Nevertheless, we individually reacted our impure intermediates 11 with putrecine (8) in a 2:1 molar ratio in anticipation of forming products $\mathbf{1}$ or 9a-b. Unfortunately, these endeavors were unsuccessful. Alternatively, we converted carboxylic acids 6 and $7 \mathbf{a}-\mathbf{b}$ into their methyl ester derivatives (not shown), which we then reacted with $\mathbf{8}$ under conditions reported by McCluskey et al. ${ }^{30}$ These attempts also failed, which effectively ended our campaign to synthesize the JBIR core through a one-pot, three-molecule strategy. 


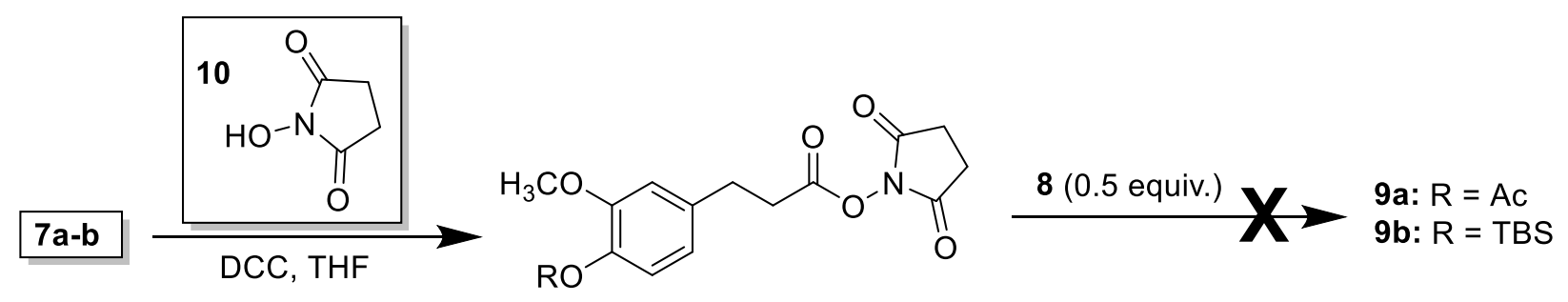

11a: $R=A c(87 \%$, impure $)$

11b: $R=$ TBS $(>100 \%$, impure)

Scheme 2. Alternative approach to the JBIR-94 core via intermediates 11a-b.

At this point, we turned to the more conservative, stepwise approach shown in Scheme 3. With concerns about potential amine cross-reactivity with acetyl or silyl protecting groups-and knowing of benzyl ethers' general robustness, putative ease of deprotection, and unreactivity toward amines ${ }^{31}$-we focused exclusively on substrate 7c from this juncture. To avoid prior obstacles with the diamine functionality of putrecine (8), we opted for commercially available, $t$ Boc-protected analog 12. Subsequent treatment of its free amine with $7 \mathrm{c}, \mathrm{EDCl}, \mathrm{Et}_{3} \mathrm{~N}$, and catalytic DMAP, followed by overnight recrystallization from $1: 1 \mathrm{CH}_{2} \mathrm{Cl}_{2} /$ hexanes, furnished 13 cleanly, in $88 \%$ yield. Deprotection was facilitated by exposure to TFA in toluene (Scheme 3). Extensive trial and error revealed that this reaction had to be quenched by adding enough $2 \mathrm{M}$ aqueous $\mathrm{NaOH}$ to bring the precipitated suspension to $\mathrm{pH}>10$. After extensive extraction (20x) with $\mathrm{CH}_{2} \mathrm{Cl}_{2}$, drying over $\mathrm{MgSO}_{4}$, concentration, and overnight recrystallization from $90 \%$ EtOAc/hexanes, product 14 was obtained in pure form in $82 \%$ yield. Renewed subjection to EDCI coupling with 7c then gave intermediate $9 \mathrm{c}$ in $85 \%$ yield (recrystallized from $\mathrm{CH}_{2} \mathrm{Cl}_{2}$ ), and $\mathrm{Pd}$ catalyzed hydrogenation concomitantly removed both benzyl groups to furnish JBIR-94 (1) in 84\% yield (52-54\% overall yield from 5$)$.

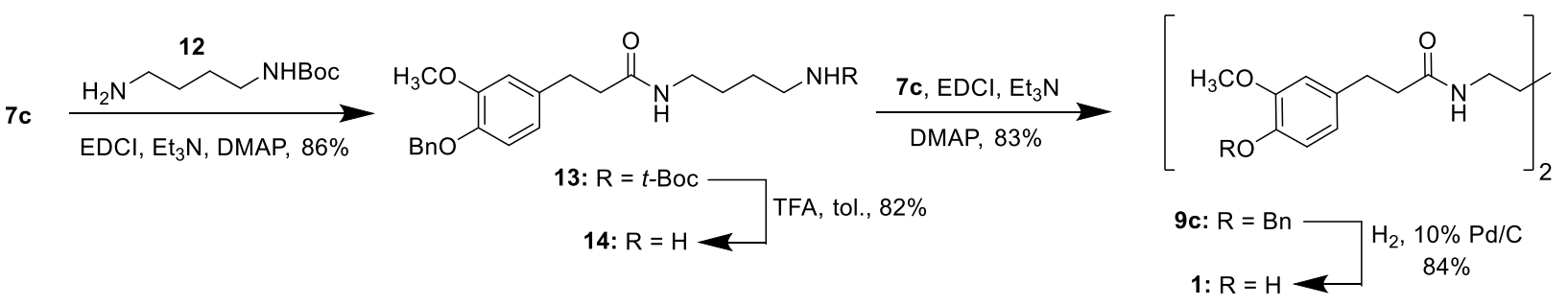

Scheme 3. Completed synthesis of JBIR-94 (1).

We next turned to analogs 3 and 4 . Thus, commercial reactant 15a was converted over two steps to 15c, the methoxy-free surrogate of 7c (Scheme 4). Next, EDCl coupling with 12 provided 16 quantitatively, and TFA-mediated deprotection formed 17 in $78 \%$ yield. Renewed coupling with 15c then gave 18 in 53\% yield, and subsequent deprotection afforded 3 in $92 \%$ yield (26\% overall yield from 15a). 


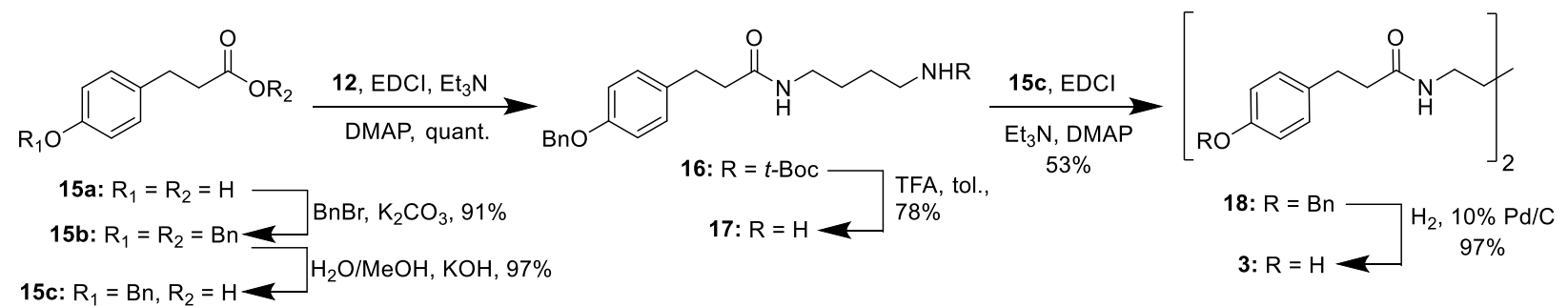

Scheme 4. Completed synthesis of JBIR-94 analog 3.

The synthesis of diamide 4 was carried out by coupling 3-phenylpropionic acid (19) with 12 to afford 20 quantitatively (Scheme 5). Deprotection, followed by subsequent coupling with 19, then gave target molecule $\mathbf{4}$ in $98 \%$ over two steps from 20.

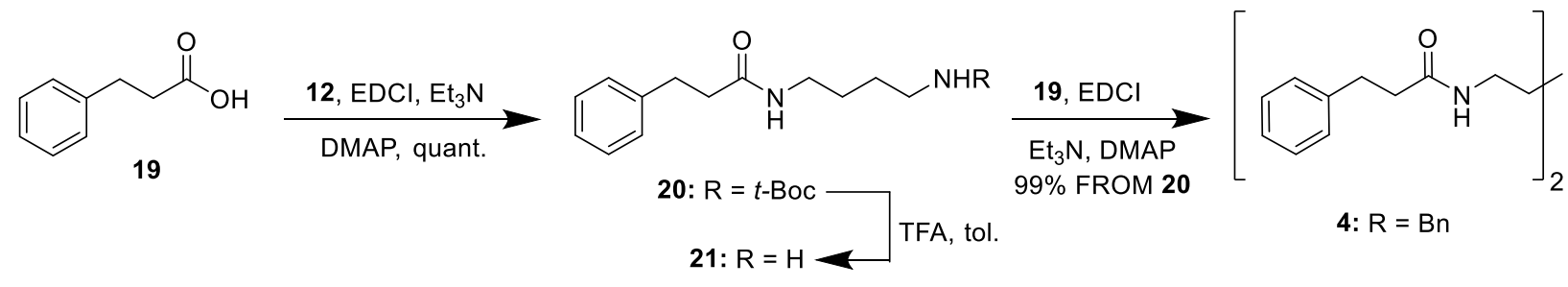

Scheme 5. Completed synthesis of JBIR-94 analog 4.

\section{Cytotoxicity Assay}

The cytotoxicities of JBIR-94 and analogs 3-4 were evaluated through a colorometric assay against A549 (CCL-185) (human small lung cancer) cells using MTT (3-(4,5-dimethylthiazol-2-yl)2,5-diphenyltetrazolium bromide) dye. For this, $200 \mu \mathrm{L}$ of cell suspension in growth medium with 5000 cells was seeded to the wells of a 96-well culture plate and incubated for 24 hours. The medium was removed, and the compounds were added to the cells across a concentration gradient $(0.01,0.1,1.0,10$, and $100 \mu \mathrm{M})$ in growth medium. Our assay also included a control with only medium and a control with $1 \% 100 \mathrm{X}$ Triton in medium. Cells were then incubated for 48 hours, and $20 \mu \mathrm{L}$ of MTT dye ( $5 \mathrm{mg} / \mathrm{mL}$ stock) was added to each well and incubated for another 5 hours. The medium was removed, the cells were washed with PBS $(\mathrm{pH}=7.4)$, and the reduced MTT dye was dissolved in $100 \mu \mathrm{L}$ of DMSO, with absorption being measured at $570 \mathrm{~nm}$ and 650 $\mathrm{nm}$. This experiment was performed in triplicate of triplicate, with mean cytotoxicities presented in Figure 2. Our results indicated that compound 4 has relative cell viability at around $55 \%$ at 100 $\mu \mathrm{M}$, whereas JBIR-94 and analog 3 are relatively more toxic, with cell viabilities at around $60 \%$, even at $10 \mu \mathrm{M}$ concentration. Moreover, JBIR-94 and compounds 3-4 have $\mathrm{IC}_{50}$ values of 52.88 $\pm 11.69 \mu \mathrm{M}, 78.92 \pm 8.92 \mu \mathrm{M}$, and $>100 \mu \mathrm{M}$, respectively, showing mild toxicity to human lung cells. 


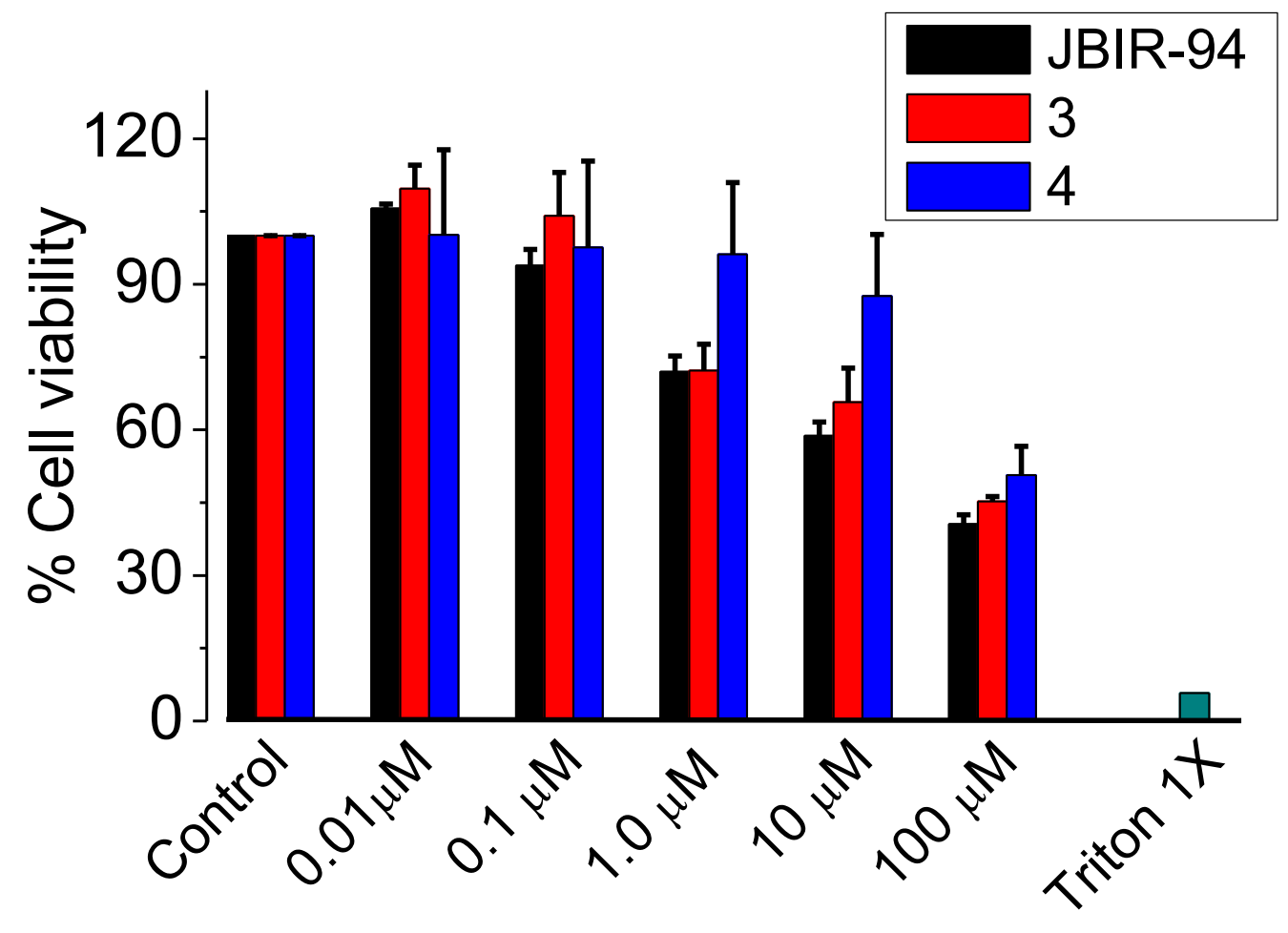

Figure 2. Gradient cytotoxicities of JBIR-94 and analogs 3-4 towards A549 (CCL-185) cells.

\section{Conclusions}

In conclusion, we disclose here the total syntheses of the natural product JBIR-94 (1), as well as nonnatural analogs 3 and $\mathbf{4}$. Although syntheses of 1 and $\mathbf{4}$ have been reported previously in the literature, ${ }^{22-23}$ compound 3 has not. Additionally, we measured the cytotoxicities and $\mathrm{IC}_{50}$ values of 1, 3, and 4 against A549 (CCL-185) human small lung cancer cells using an MTT colormetric assay. Our results indicated that analog 4 has relative cell viability at around 55\%, whereas 1 and 3 are relatively more toxic, with cell viabilities at around $60 \%$, even at $10 \mu \mathrm{M}$ concentration. Separately, 1, 3, and 4 have $\mathrm{IC}_{50}$ values of $52.88 \pm 11.69 \mu \mathrm{M}, 78.92 \pm 8.92 \mu \mathrm{M}$, and >100 $\mu \mathrm{M}$, respectively, showing mild toxicity to human lung cells.

\section{Acknowledgments}

The authors would like to thank Professors Steven L. Castle and Merritt Andrus from BYU, as well as Dr. Tom Chang from USU, for their suggestions and contributions during difficult junctures of this project. The authors gratefully acknowledge funding from the Uintah Basin Impact Mitigation Fund, the Utah State University (USU) Uintah Basin Summer Internship Program, and the USU Department of Chemistry and Biochemistry.

\section{Supplementary data}


Supplementary data associated with this article, which include complete experimental procedures and spectral characterization $\left({ }^{1} \mathrm{H}\right.$ and ${ }^{13} \mathrm{C}$ NMR), are available in the online version at.

\section{References and notes}

1. Shen, Q.; Zhang, B.; Xu, R.; Wang, Y.; Ding, X.; Li, P. Anaerobe 2010, 16, 380-386.

2. Seifried, H.E.; Anderson, D.E.; Fisher, E. I.; Milner, J. A. J. Nutr. Biochem. 2007, 18, 567- 579.

3. Singh, S.; Singh, R. P. Food Rev. Int. 2008, 24, 392-415.

4. Kedare, S. G.; Singh, R. P. J. Food Sci. Technol. 2011, 48, 412-422.

5. Aruoma, O. I. J. Am. Oil Chem. Soc. 1998, 75, 199-212.

6. Sánchez-Moreno, C.; Larrauri, J. A.; Saura-Clixto, F. J. Sci. Food Agric. 1998, 76, 270-276.

7. Jacob, R. A. Nutr. Res. 1995, 15, 755-766.

8. Lee, Y.; Howard L. R.; Villalón, B. J. Food Sci. 1995, 60, 473-476.

9. Yen, G.-C.; Chen, H.-Y. J Agric Food Chem. 1995, 43, 27-32.

10. Salah, N.; Miller, N. J.; Paganga, G.; Tijburg, L.; Bolwell, G. P.; Rice-Evans, C. Arch Biochem Biophys. 1995, 332, 339-346.

11. Vinson, J. A.; Hontz, B. A. J. Agric. Food Chem. 1995, 43, 401-403.

12. Kanner, J.; Frankel, E.; Granit, R.; German, B.; Kinsella, J. E. J. Agric. Food Chem 1994, 42, 64-69.

13. Tamura, H.; Yamagami, A. J. Agric. Food Chem. 1994, 42, 1612-1615.

14. Huang, M. T.; Ferraro, T. Phenolic Compounds in Food and Cancer Prevention. In Phenolic Compounds in Food and Their Effects on Health II; ACS Symposium Series 507; American Chemical Society: Washington, DC, 1992; pp 8-34.

15. Goldinga, B. T.; O’Sullivan, M. C.; Smith, L. L. Tetrahedron Lett. 1988, 29, 6651-6654.

16. Noguchi, N.; Komuro, E.; Niki, E.; Wilson, R. L. J. Jpn. Oil Chem. Soc. 1994, 43, 1045-1051.

17. Kinsella, J. E.; Frankel, E.; German, B.; Kanner, J. Food Technol. 1993, 47, 85-89.

18. Kawahara, T.; Izumikawa, M.; Otoguro, M.; Yamamura, H.; Hayakawa, M.; Takagi, M.; Shinya, K. J. Nat. Prod. 2012, 75, 107-110.

19. Shao, H.-B.; Chu, L.-Y.; Lu, Z.-H.; Kang, C.-M. Int. J. Biol. Sci. 2008, 4, 8-14.

20. Traber, M. G.; Atkinson, J. Free Radic. Biol. Med. 2007, 43, 4-15.

21. Christiansen, M. A.; Crawford, C. L.; Mangum, C. D. Chem. Educ. 2014, 19, $28-33$.

22. Taj, R.; Sorensen, J. L. Tetrahedron Lett. 2015, 56, 7108-7111.

23. Xiong, S.; Zhang, X.; Meng, L.-B.; Jiang, J.; Lin, C.; Wang, L. Chem. Commun. 2015, 51, 6504-6507.

24. (a) Sato, O.; Tanbo, A. Heterocycles. 2004, 64, 357-366. (b) Wiznycia, A. V.; Rush, J. R.; Baures, P. W. J. Org. Chem. 2004, 69, 8489-8491.

25. Fumeaux, R.; Menozzi-Smarrito, C.; Stalmach, A.; Munari, C.; Kraehenbuehl, K.; Steiling, H.; Crozier, A.; Williamson, G.; Barron, D. Org. Bioomolec. Chem. 2010, 8, 5199-5211.

26. Boschi, D.; Tron, G. C.; Lazzarato, L.; Chegaev, K.; Cena, C.; Di Stilo, A.; Giorgis, M.; Bertinaria, M.; Fruttero, R.; Gasco, A. J. Med. Chem. 2006, 49, 2886-2897.

27. (a) Bazin, M.-A.; El Kihel, L.; Jouanne, M.; Lancelot, J.-C.; Rault, S. Synth. Commun. 2008, 38, 3947-3959. (b) Snyder, S. A.; Kontes, F. J. Am. Chem. Soc. 2009, 131, 1745-1752.

28. Leschot, A.; Tapia, R. A.; Eyzaguirre, J. Synth. Commun. 2002, 32, 3219-3223.

29. (a) Becerril, J.; Bolte, M.; Burguete, M. I.; Galindo, F.; García-España, E.; Luis, S. V.; Miravet, J. F. J. Am. Chem. Soc. 2003, 125, 6677-6686. (b) Basha, A.; Lipton, M.; Weinreb, S. M. Tetrahedron Lett. 1977, 18, 4171-4174.

30. Hill, T. A.; Sakoff, J. A.; Robinson, P. J.; McCluskey, A. Aust. J. Chem. 2004, 58, 94-103.

31. Wuts, P. G. M. Greene's Protective Groups in Organic Synthesis, 5th ed.; John Wiley \& Sons: Hoboken, New Jersey, 2014. 